\title{
Social Positions in the City of Light
}

\author{
Craig R. Lundahl, Ph.D. \\ Western New Mexico University
}

Harold A. Widdison, Ph.D.

Northern Arizona University

ABSTRACT: This article describes the social positions of inhabitants in the otherworldly City of Light as reported by a limited number of Mormon neardeath experiencers (NDErs). These social positions included men and women and various relatives and friends, in addition to authorities or administrators, genealogists, guardians, guides, homemakers, missionaries, teachers, and students. These reports of social positions in the City of Light are similar to those described by other researchers, and are comparable to those found in our own world.

Individuals who have been declared clinically dead because their vital functions had ceased, but who have revived and reported being aware of what happened to them during the interim, have had what is called a near-death experience (NDE). Those who have had NDEs are usually convinced that they were truly dead and that what they experienced was very real.

Although accounts of these experiences have received considerable attention from contemporary researchers, they were also the focus of writers more than 800 years ago in The Tibetan Book of the Dead

Craig R. Lundahl, Ph.D., is Professor of Sociology and Business Administration and Chair of the Department of Social Sciences at Western New Mexico University. Harold A. Widdison, Ph.D., is Professor of Sociology at Northern Arizona University. The authors thank Jay G. Burrup for providing a section of the Diary of George Henry Carver. This research was supported in part by a sabbatical leave granted to Dr. Lundahl by the Sabbatical Leave Committee of Western New Mexico University. 
(Evans-Wentz, 1957) and 4,000 years ago in The Egyptian Book of the Dead (Budge, 1967). Raymond Moody was probably the most influential contemporary author on the NDE; he described and labelled the NDE and identified 15 elements of the experience (1975), and noted that not all of the stages were experienced by all NDErs, a fact corroborated by Kenneth Ring $(1980,1984)$ and other near-death researchers. Many NDErs feel a sense of peace, a life review, and a sense that they had left their physical bodies; however, about 11 percent report encountering another realm, usually termed heavenly, while experiencing a near-death state (Gallup and Proctor, 1982). Moody (1977) called this other realm "cities of light."

Craig Lundahl (1981-82) described the social system in the other realm as perceived by Mormon NDErs; he specifically outlined the social structure, social interaction, social stratification, social control, and socialization activities in "cities of light." Since then, new material on NDEs has been collected and published, from old diaries and journals and from contemporary sources. What is even more interesting is that the old and new accounts do not contradict each other; rather they complement one another and provide us with additional information on the social aspects of the "cities of light."

The purpose of this article is to look at past and newly published Mormon NDE accounts to learn more about the social positions in the cities of light. Both Elisabeth Kubler-Ross (personal communication, 1980) and Moody (personal communication, 1985) have noted that this particular religious group, officially known as The Church of Jesus Christ of Latter-Day Saints but commonly known as Mormons, seems to report not only very detailed and rich NDE accounts but, for the size of the group, a surprisingly large number of such experiences predating the current flood of NDE reports. We will identify social positions observed by Mormons who reported visiting a "City of Light" during an $\mathrm{NDE}$, and will compare these data with the published findings of other near-death researchers.

We will limit the present analysis of NDE reports to those published and unpublished accounts reported by Mormons. There are three reasons for choosing this particular group for detailed analysis. The first is their rich tradition of recorded NDEs, as noted above; Mormons are encouraged to keep journals and to record significant events affecting themselves and their families, and therefore any NDEs that occurred would have a very high probability of being written down. Second, Mormons are encouraged to share their significant experiences with fellow Mormons, and their NDEs are therefore likely to come to the attention of others. And third, Mormon NDEs tend to parallel their 
religious beliefs in both content and interpretation (Lundahl and Widdison, 1983).

\section{Social Statuses in the City of Light Reported by Mormon NDErs}

Social statuses are socially defined positions that people occupy in a group or society. Karlis Osis and Erlendur Haraldsson (1977) noted that the people their informants met in deathbed visions had two primary social positions: the first was to serve as a guide to and in the afterlife, and the second was that of a notifier who was to forewarn the NDEr that he or she was about to die. However, an analysis of Mormon NDEs indicates a much larger number of social positions in the other world. Social positions identified in the City of Light include but are not limited to men, women, husbands, wives, fathers, mothers, children, grandparents, other relatives and friends, authorities or administrators, genealogists, guardians, guides, homemakers, missionaries, teachers, and students.

\section{Gender and Friendships}

Mormon NDErs have observed both men and women in the City of Light (Lundahl, 1981-82). The status of friend is also found in the City of Light (Lundahl, 1982; Nelson, 1989). Close friendships that existed on earth continue in the City of Light, friends are greeted with excitement, news and information are shared, and new arrivals are introduced to others.

\section{Relatives}

Many Mormon NDErs have seen and/or visited with deceased husbands, wives, children, grandparents, and other relatives (Lundahl, 1981-82). People seen in the City of Light were described by Mormon NDErs as being organized in family capacities (Lundahl, 1981-82) or in family relationships (Nelson, 1988). These two observations suggest that the positions or statuses of husband, wife, father, mother, son, daughter, brother, sister, grandfather, grandmother, aunt, uncle, cousin, nephew, niece, father-in-law, mother-in-law, brother-in-law, and sister-in-law are found in the City of Light, and furthermore that 
role expectations, rights, and obligations between the NDErs and the observed relatives continue along familial lines in the other world.

\section{Authorities}

Sometimes NDErs are sent back to mortal life. Often it is reported that some authorities in the afterlife meet with recent arrivals and inform some of them that their purpose on earth has not yet been completed and therefore they must return. Some NDErs were told that their deceased relatives had petitioned that they be sent back to do work for them that they could not do for themselves in the afterlife (Nelson, 1988, 1989). Eliza Ursenbach was told that because of the faith of her family, she would be given the opportunity to return to life and rear her two small children (Heinerman, 1978). In another case, a man observed the deceased members of his family meeting around a large table, discussing what should be done to help a family member still on earth-in this case, his daughter. Their decision was that he must return to help her over a major crisis she was experiencing ( $R$. Widdison, personal correspondence, 1985).

It appears that regardless of the individual's personal desires, permission to return to life must be granted by appropriate authorities; if the desire to live is for positive and productive reasons, it might be granted (Nelson, 1988). It appears that individuals are not forced to return to their bodies, however; that seems to be a voluntary decision. Some who expressed great reluctance to return were shown what would happen to their families if they did not (Lundahl, 1982). The consequences were enough to convince them to return. It is important to note that Mormon NDEs suggest an order and grades of status in the other world that are not seen on earth (Carver, 1881; Lundahl, 198182), so we might expect to find a hierarchy of authority there.

\section{Genealogists and Couriers}

As Harriet Beal traveled in the other world, she saw a large room filled with individuals rapidly recording genealogical data (Heinerman, 1978). Some NDErs were used as "couriers" to carry genealogical information to those still on earth, which could not be identified in any other way. A number of NDErs reported being sent back to their bodies so they could do genealogical work at the request of their relatives in the afterlife. 


\section{Guardians, Escorts, and Guides}

In many accounts individuals were told that they would have to return to life to complete some unfinished work, even though their recovery would be lengthy and very painful due to the trauma their bodies had experienced when they died. They were promised that they would receive the constant support and guidance of a guardian angel (Nelson, 1989). One Mormon NDEr specifically mentioned the appearance of a guardian angel in his NDE (Crowther, 1967).

One apparent function of a guardian is to meet those who die, "escort" them as they enter the afterlife, and report their presence to the appropriate authority. One young man was told by his escort that his sister wanted to see him and to wait, as she had to finish what she was doing before she could come. The major reason for this meeting was a pact they had made with each other while on earth that whoever died first would watch over the other while he or she was still living (Crowther, 1967).

All Mormons reporting an indepth NDE seemed to have had some type of guide assigned to them. For most respondents, it was a deceased close relative, such as a spouse, parent, sibling, child, or grandparent. For others, the guide was a distant relative or friends; while for still others, the guide was some kind of ecclesiastical figure. For example, Larry Tooley, who was killed when he fell from scaffolding, met an old friend who informed him he was to be his guide until he became oriented; and Carlos Hjorth met several people in white flowing robes, one of whom was to be his escort (Nelson, 1988).

\section{Missionaries and Teachers}

One Mormon NDEr saw one of his brothers-in-law in the other world serving as a mission president (Crowther, 1967), and another Mormon NDEr saw missionary services being conducted (Heinerman, 1978).

Ella Jensen, a Mormon NDEr, observed a group convened in a school setting presided over by a relative (Crowther, 1967). She saw a large group of children being taught. Among these children was one who she knew was still alive; upon recovery, she reported her experience and was informed that the child had died earlier that morning (Crowther, 1967). Another Mormon NDEr saw a deceased woman, whom he had formerly known, in charge of a number of small children in a school class (Carver, 1881). 


\section{Homemakers and Other Statuses}

Harriet Beal learned in the City of Light that persons there have commonplace tasks to perform: she asked her deceased mother if she worked in the kitchen, and her mother said that she takes her turn (Crowther, 1967). One Mormon NDEr reported that he joined others in the City of Light in eating and drinking (Carver, 1881). This information suggests that many domestic tasks are performed in the City of Light.

Mormon NDErs also reported seeing people writing family records, painting, cooking, building large houses, participating in meetings, playing music, singing in choirs, considering petitions, preaching, and presiding over various subgroupings.

In examining Mormon NDEs, the social activities observed can be classified into seven categories: (1) gaining knowledge and understanding, (2) assisting those on earth who need help, (3) preparing for future events, (4) teaching, (5) developing musical skills, (6) researching family records, and (7) accomplishing routine and major tasks.

\section{Findings of Other Near-Death Researchers}

NDEs reported by other near-death researchers include references to social positions as men, women, husbands, mothers, fathers, grandparents, and other relatives (Gallup and Proctor, 1982; Green and Friedman, 1983; Morse and Perry, 1990; Ring, 1980; Sabom, 1982). The Gallup Poll's survey of NDEs found descriptions of a hierarchy of authority, angels, guides, instructors, and individuals making choir robes (Gallup and Proctor, 1982).

These findings corroborate the descriptions from Mormon NDErs of social positions in the City of Light with the exception of two positions: genealogists and missionaries. There are a number of possible explanations for these exceptions. First, Mormon and nonMormon NDErs may label the same activities differently: activities identified by Mormon NDErs as missionary service and genealogy work may be labelled by nonMormon NDErs as teaching, research, and record keeping. Another possible explanation could be the location of these missionary and genealogical activities in the City of Light: it may be that visitors to this location are limited to a few groups like Mormon NDErs. Furthermore, it is possible that cultural factors have influenced the kinds of observations made by NDErs, and that Mormon NDErs were more attuned to genealogical and missionary activities and therefore 
more likely to identify them in subsequent reports. Finally, there may simply have been too few descriptions of the City of Light published by other near-death researchers to include all the social positions found there, so that we can expect further reports of the City of Light by nonMormon NDErs to document genealogists and missionaries as well.

\section{Conclusion}

According to Mormon NDE accounts, the other world or the City of Light is a place where people are involved in numerous activities and in many social positions. These positions are highly organized in familial and institutional hierarchies. Order exists and is controlled by some apparent ecclesiastical system. Individuals occupy many different statuses or positions that include occupational categories as we know them, ranging from white collar workers to service workers.

This list of statuses is undoubtedly but a small representation of the positions occupied by people in the City of Light. Lundahl noted previously that the other world as perceived by Mormons during NDEs was not so unlike our own world (1981-92). We can aptly conclude this study by noting that the social positions found in the other world are not so unlike those found in our own world. Yet it may also be that some statuses we have, such as health workers and protective service workers or prison guards, are not required in the City of Light, even though they are still essential careers in this world (Nelson, 1989).

\section{References}

Budge, E. A. W. (Ed.). (1967). The Egyptian book of the dead. New York, NY: Dover.

Carver, G. H. (1881). Diary of George Henry Carver. Unpublished manuscript in the possession of Jay G. Burrup.

Crowther, D. S. (1967). Life everlasting. Salt Lake City, UT: Bookcraft.

Evans-Wentz, W. Y. (Ed.). (1957). The Tibetan book of the dead (3rd ed.). London, England: Oxford University Press.

Gallup, G., Jr., and Proctor, W. (1982). Adventures in immortality: A look beyond the threshold of death. New York, NY: McGraw-Hill, 1982.

Green, T. J., and Friedman, P. (1983). Near-death experiences in a Southern California population. Anabiosis: The Journal of Near-Death Studies, 3, 77-95.

Heinerman, J. (1978). Spirit world manifestations. Salt Lake City, UT: Magazine Printing and Publishing.

Lundahl, C. R. (1981-82). The perceived other world in Mormon near-death experiences: A social and physical description. Omega, 12, 319-327. 
Lundahl, C. R. (1982). Near-death experiences of Mormons. In Lundahl, C. R. (Ed.), A collection of near-death research readings (pp. 165-179). Chicago, IL: Nelson-Hall.

Lundahl, C. R., and Widdison, H. A. (1983). A comparison of LDS conceptions of the afterlife and the afterlife in LDS near-death experiences. Journal of Religion and Psychical Research, 6, 288-294.

Moody, R. A., Jr. (1975). Life after life. Covington, GA: Mockingbird.

Moody, R. A., Jr. (1977). Reflections on life after life. St. Simon's Island, GA: Mockingbird.

Morse, M., and Perry, P. (1990). Closer to the light: Learning from the near-death experiences of children. New York, NY: Villard.

Nelson, L. (1988). Beyond the veil. Volume one. Orem, UT: Cedar Fort.

Nelson, L. (1989). Beyond the veil. Volume two. Orem, UT: Cedar Fort.

Osis, K., and Haraldsson, E. (1977). At the hour of death. New York, NY: Avon.

Ring, K. (1980). Life at death: A scientific investigation of the near-death experience. New York, NY: Coward, McCann and Geoghegan.

Ring, K. (1984). Heading toward omega: In search of the meaning of the near-death experience. New York: NY: William Morrow.

Sabom, M. B. (1982). Recollections of death: A medical investigation. New York, NY: Harper and Row. 